\title{
Accelerated idioventricular rhythm of infundibular origin in patients with a concealed form of arrhythmogenic right ventricular dysplasia
}

\author{
BORTOLO MARTINI, ANDREA NAVA, GAETANO THIENE, * \\ GIAN FRANCO BUJA, BRUNO CANCIANI, GIUSEPPE MIRAGLIA, \\ ROLDANO SCOGNAMIGLIO, GIOVANNI MARIA BOFFA, LUCIANO DALIENTO
}

From the Departments of Cardiology and *Pathology, University of Padua, Italy

SUMMARY Five apparently healthy people (aged 16-47) presented with recurrent episodes of accelerated idioventricular rhythm characterised by left bundle branch block and right axis deviation. Clinical history, physical findings, basic electrocardiogram, chest $x$ ray, and blood tests were within normal limits in all. Holter monitoring, exercise stress test, and electrophysiological study (in three patients) showed that accelerated idioventricular rhythm was mainly bradycardia dependent, easily suppressed by effort and overdrive pacing, and originated from the outflow tract of the right ventricle. The mechanism could be enhanced automaticity. Data from cross sectional echocardiography (in all patients) and from haemodynamic evaluation (in three) identified structural or wall motion abnormalities of the right ventricle or both without appreciable dilatation of the ventricle. Biopsy specimens of the right ventricular endomyocardium showed fibrosis in one patient, fibrosis and fatty infiltration in the second, and pronounced fatty infiltration in the third.

These results show that some patients with accelerated idioventricular rhythm have right ventricular abnormalities that are typical of the localised and concealed forms of arrhythmogenic right ventricular dysplasia.

Intermittent ectopic idioventricular rhythms at rates of between 40 and 120 beats per minute have been described as accelerated idioventricular rhythms. ${ }^{12}$

Accelerated idioventricular rhythm is common in patients with acute myocardial infarction..$^{1-5}$ Other conditions causing this arrhythmia include myocarditis, digitalis intoxication, and congenital atrioventricular block. ${ }^{1367}$ The configuration of the QRS complex during accelerated idioventricular rhythm may be that of either a right bundle branch block or (more often) a left bundle branch block..$^{1-9}$ Enhanced automaticity ${ }^{1}$ or parasystole ${ }^{8}$ have been suggested as possible mechanisms for the arrhythmia. In young people accelerated idioventricular rhythm is rare, and to date there is no correlation established with any well known cardiac pathology. ${ }^{1289}$

We report five apparently healthy people present-

Requests for reprints to Dr Bortolo Martini, Via Gioberti 9, 36016 Thiene (VI), Italy.

Accepted for publication 5 November 1987 ing with accelerated idioventricular rhythm characterised by left bundle branch block and right axis deviation in whom we found right ventricular abnormalities.

\section{Patients and methods}

Five patients (four men and one woman; mean age 26 (range 16-47)), were examined because they had accelerated idioventricular rhythm characterised by left bundle branch block and right axis deviation. None was taking any drug. All were assessed by clinical history, chest $x$ ray, blood tests, 24 hour continuous electrocardiographic (Holter) monitoring, and symptom limited exercise stress testing (on a bicycle ergometer with standard protocols). We performed vectorcardiography on all five patients during the arrhythmia (in the supine position), with a Fukuda VA-3G instrument, using the Frank Lead system and dash time interval of $2 \mathrm{~ms}$. Three patients were examined in an electrophysiological and haemodynamic- angiographic study and by right ventricular endomyocardial biopsy. 


\section{Accelerated idioventricular rhythm}

Cross sectional echocardiographic images were recorded in all patients on a Hewlett-Packard system and with a 2.5 or $3.5 \mathrm{MHz}$ transducer. Images were obtained in multiple standard views: parasternal, long and short axis; apical, four and two chamber (left and right); and subcostal, four chamber and short axis. Subjects were imaged in either the supine or left lateral recumbent position. The images were examined by two observers for regional wall motion or structural abnormalities of the right and left ventricles or both. ${ }^{10-13}$ The right ventricular volume (corrected by the regression equation, according to age and body surface area) was calculated by an arealength method derived from orthogonal planes (apical four chamber and long axis views). A modified Simpson's rule was used to calculate left ventricular volumes from the parasternal short axis and apical two chamber views. The ejection fraction of both ventricles was derived as: $\mathrm{EF}=\mathrm{EDV}-\mathrm{ESV} / \mathrm{EDV}$, where EF is the ejection fraction and EDV and ESV are end diastolic and end systolic volumes respectively. Infundibular diameter was determined from the parasternal short axis view of the aortic root. The right ventricular outflow tract was measured from this view as the maximum dimension between the anterior aortic wall and the endocardium of the free wall of the right ventricle. ${ }^{12}$

A haemodynamic-angiographic examination and right ventricular endomyocardial biopsy were performed in the three patients who agreed to the procedure. Haemodynamic study included left and right ventricular angiography, coronary arteriography, and the recording of pressures in various cavities. Angiocardiograms of the right ventricle were obtained in posteroanterior, lateral, and long axis (oblique right and left anterior) projections, for better definition of the infundibulum and posterobasal wall. The angiocardiograms of the left ventricle were performed in the $30^{\circ}$ left anterior oblique and right anterior oblique projections. We calculated right ventricular volumes from biplane angiocardiography, using anteroposterior and lateral views (area-length method). ${ }^{14-16}$ and left ventricular volumes from monoplane cineangiography using $30^{\circ}$ right anterior oblique view. ${ }^{15}$ The measured volumes were corrected with a regression equation according to age and body surface. The motion of the right ventricular wall was analysed on the anterior and posterior silhouettes of the infundibulum and on the posterobasal and apical regions. Finally, the trabecular framework was carefully examined. ${ }^{16}$ Biopsy specimens of the right ventricular endomyocardium were obtained via the right femoral vein by a standard technique. ${ }^{17-19}$ Six biopsy specimens (1-3 mm each), taken from the interventricular septum in each patient, were fixed in formalin, mounted in paraffin wax, and stained with haematoxylin-eosin and azan-Mallory.

Patients 1,2, and 3 were also studied electrophysiologically; real time records were obtained with an ink jet recorder (Siemens-Elema, Mingograph) with a filter setting of $50-70 \mathrm{~Hz}$ for the intracavitary electrocardiograms, at a paper speed of $100 \mathrm{~mm} / \mathrm{s}$. Basic conduction (PA, AH, HV) intervals were measured. The right ventricular endocardium was accurately mapped to localise the origin and the successive spread of the accelerated idioventricular rhythm, and to detect late fractionated potentials of QRS. Stimulation was performed with a customdesigned, multiprogrammable stimulator (PPS 500, Medico Italy) with a constant current source and rectangular impulse of $1 \mathrm{~ms}$ duration delivered at twice diastolic threshold.

The following protocol was then used to precipitate ventricular arrhythmias, to evaluate the entire conduction system, and to reproduce the

Table 1 Clinical data and results of chest $x$ ray, electrocardiogram, and exercise stress test in the five patients

\begin{tabular}{|c|c|c|c|c|c|}
\hline & Case 1 & Case 2 & Case 3 & Case 4 & Case 5 \\
\hline $\begin{array}{l}\text { Age } \\
\text { Sex } \\
\text { Follow up (years) } \\
\text { Symptoms } \\
\text { CT index } \\
\text { Inverted T waves } \\
\text { AIR: }\end{array}$ & $\begin{array}{l}47 \\
F \\
10 \\
P, S \\
0 \cdot 45 \\
\text { V1, V2, V3 }\end{array}$ & $\begin{array}{l}16 \\
M \\
2 \\
P \\
0 \cdot 53 \\
-\end{array}$ & $\begin{array}{l}21 \\
M \\
5 \\
P \\
0 \cdot 50 \\
\text { V1 }\end{array}$ & $\begin{array}{l}35 \\
M \\
2 \\
P \\
0 \cdot 48 \\
\text { V1 }\end{array}$ & $\begin{array}{l}16 \\
M \\
2 \\
P \\
0 \cdot 45 \\
-\end{array}$ \\
\hline $\begin{array}{l}\text { AIR: } \\
\text { RR interval } \\
\text { aQRS } \\
\text { QRS configuration } \\
\text { QRS configuration in V1 }\end{array}$ & $\begin{array}{l}1040 \\
+110 \\
\text { LBBB } \\
\text { qrS }\end{array}$ & $\begin{array}{l}640 \\
+110 \\
\text { LBBB } \\
\text { rS }\end{array}$ & $\begin{array}{l}840 \\
+110 \\
\text { LBBB } \\
\text { rS }\end{array}$ & $\begin{array}{l}1000 \\
+110 \\
\text { LBBB } \\
\text { rS }\end{array}$ & $\begin{array}{l}1000 \\
+110 \\
\text { LBBB } \\
\text { rS }\end{array}$ \\
\hline $\begin{array}{l}\text { Exercise test: } \\
\text { Maximal HR } \\
\text { Double product }(\mathrm{HR} \times \mathrm{BP}) \\
\text { Suppression of AIR at rate: }\end{array}$ & $\begin{array}{l}160 \\
25600 \\
75\end{array}$ & $\begin{array}{l}170 \\
23800 \\
98\end{array}$ & $\begin{array}{l}190 \\
32800 \\
102\end{array}$ & $\begin{array}{l}160 \\
27200 \\
90\end{array}$ & $\begin{array}{l}180 \\
28700 \\
70\end{array}$ \\
\hline
\end{tabular}

AIR, accelerated idioventricular rhythm; BP, blood pressure; CT, cardiothoracic ratio; HR, heart rate; LBBB, left bundle branch block; $P$, palpitation; S, syncope.

$\star$ On basic electrocardiogram. 
electrocardiographic configuration of the clinical accelerated idioventricular rhythm.

(a) Atrial and ventricular pacing at progressively shorter cycles;

(b) premature atrial and ventricular stimulation during sinus rhythm (the entire cycle was scanned to the point of atrial and of ventricular refractoriness);

(c) Premature atrial and ventricular pacing (S2) during atrial and ventricular pacing with a drive cycle length (S1-S1) of 500 and $700 \mathrm{~ms}$;

(d) Double ventricular stimuli (S2-S3) at progressively shorter coupling intervals, during ventricular pacing. S1-S2 was set $50 \mathrm{~ms}$ greater than the ventricular refractory period at a given cycle length. (e) Pacing of different sites of the right ventricle (inflow, apex, septum, outflow) was used in an attempt to reproduce the electrocardiographic configuration of the patient's arrhythmia.

\section{Results}

Clinical, haematological, and radiological data. All patients had palpitation and in one there was syncope (of doubtful origin) (case 1). Mean follow up, after the detection of the arrhythmia was $4 \cdot 2$ (range 2-10) years. Only patient 1 was treated (successfully) with antiarrhythmic drugs (disopyramide $800 \mathrm{mg} /$ day). Haematological data were all normal. Chest $x$ rays showed a cardiothoracic index $<0.53$ in all.
BASIC ELECTROCARDIOGRAM, VECTORCARDIOGRAM, EXERCISE STRESS TEST, AND HOLTER MONITORING DATA (TABLE 1)

All patients had normal atrioventricular and intraventricular conduction. We found inverted $T$ waves in V1-V3 in case 1 and in VI in cases 3 and 4. No late potentials were detectable on the surface electrocardiogram. Accelerated idioventricular rhythm had a left bundle branch block configuration and a QRS axis of approximately $+110^{\circ}$ in all patients. In V1 four patients had an rS pattern and one (case 1) a qrS pattern (fig 1). The diagrammatic representation of the vector loops were inscribed in a clockwise direction in the frontal plane; in the horizontal plane the initial forces had a clockwise direction, and were followed by counterclockwise rotation; the spatial loop was directed inferiorly and posteriorly. The initial QRS showed considerable slurring in all, and in four (except case 1) this complex was directed anteriorly (fig 2). The accelerated idioventricular rhythm was iterative in four and almost incessant in one (case 2). The cycle length of the accelerated idioventricular rhythm in the five patients varied from 1040 to $640 \mathrm{~ms}$. In two patients the cycle length varied by $50-200 \mathrm{~ms}$ in different episodes. The duration of the coupling interval with the preceding sinus beat ranged from 560 to $1480 \mathrm{~ms}$; there were minor variations in the individual patients $(40-80 \mathrm{~ms})$ in successive episodes.

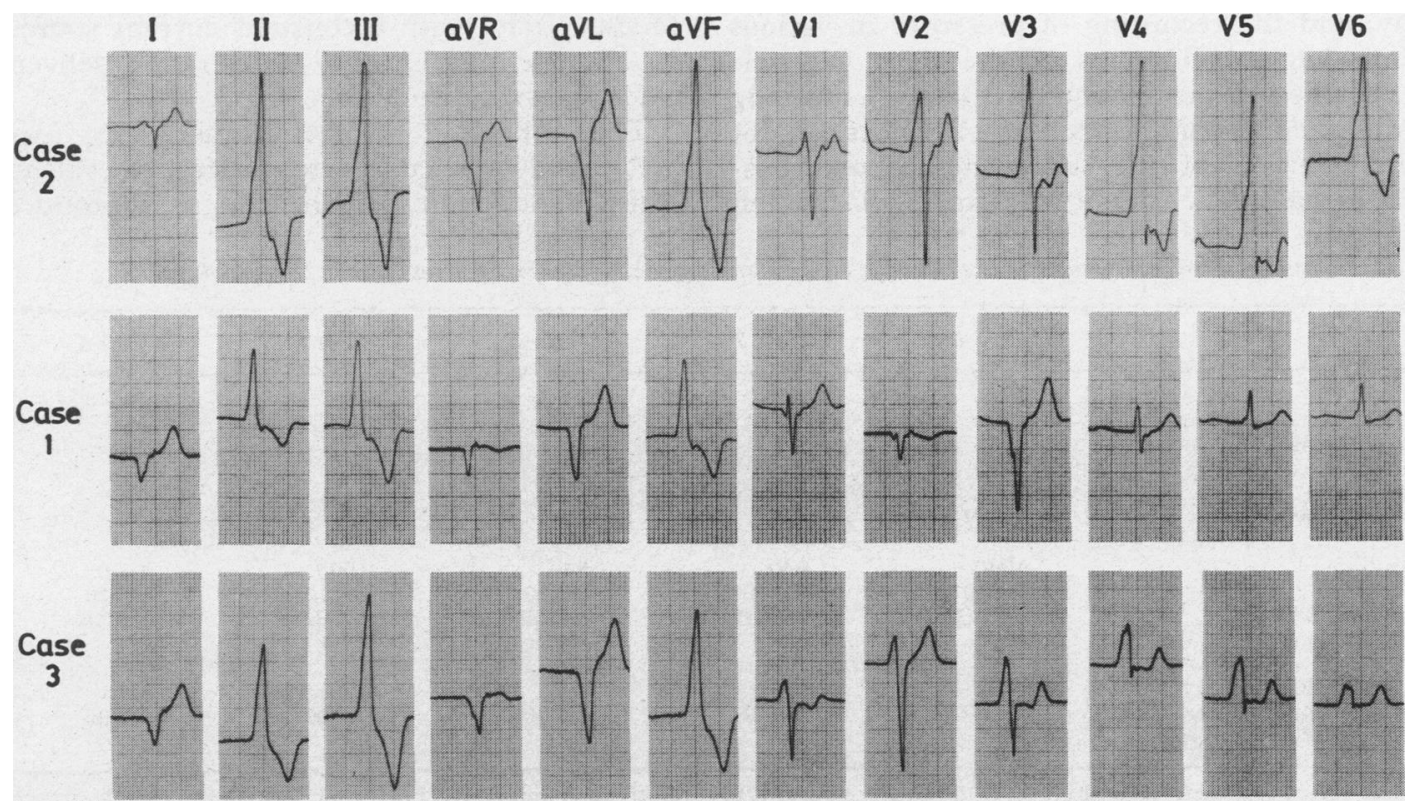

Fig 1 Twelve lead electrocardiograms from patients 1, 2, and 3 during accelerated idioventricular rhythm. There is left bundle branch block and right axis deviation shown in all. Patients 1 and 3 have an rS pattern in $V 1$ indicating the posterior origin of the arrhythmia. 


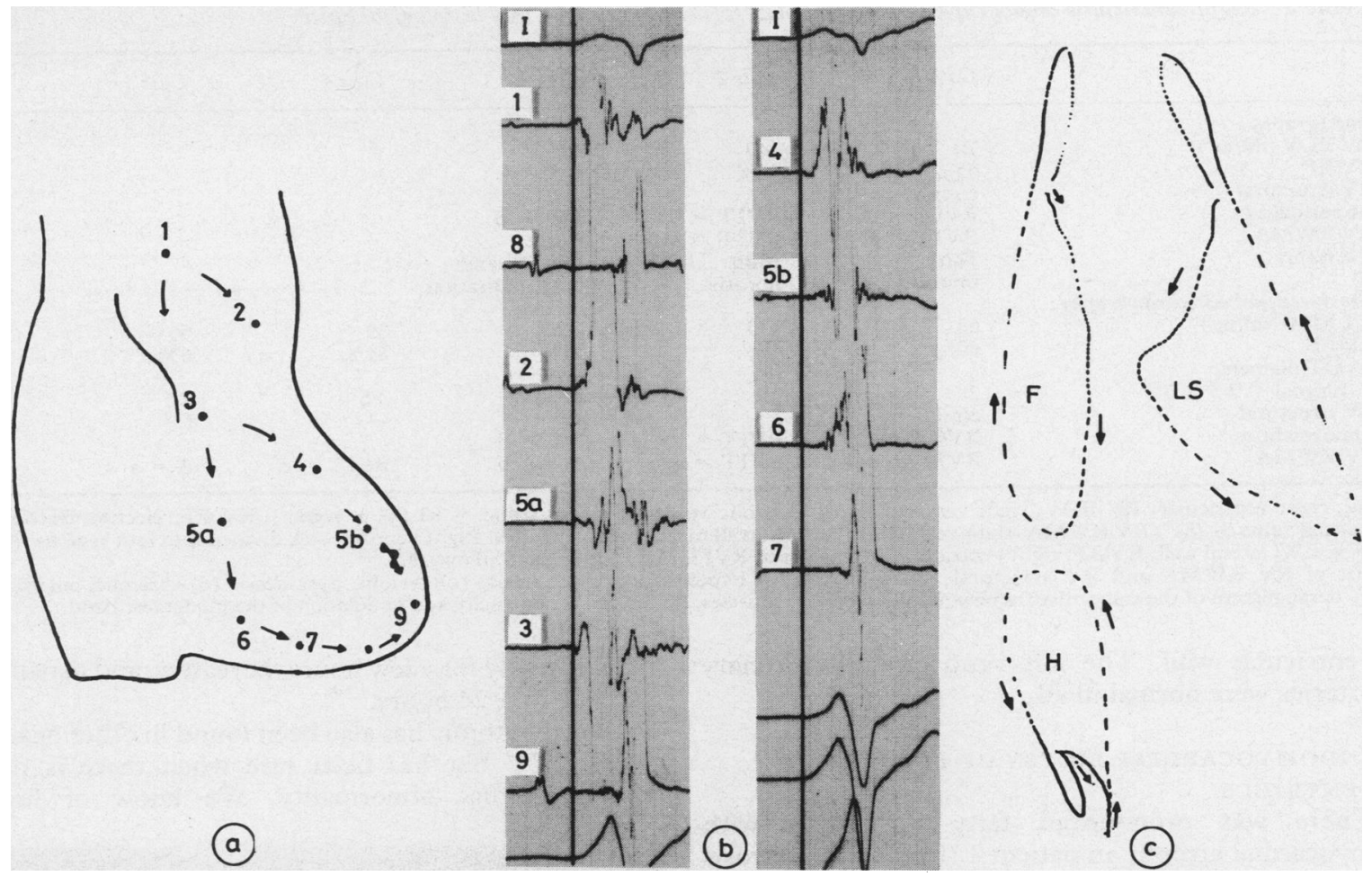

Fig 2 Right ventricular endocavitary mapping (a,b) and vectorcardiogram (c) of patient 2. (a) Right ventricular activation pattern during accelerated idioventricular rhythm constructed from data are derived from the endocavitary electrocardiographic recordings (b) obtained during the accelerated idioventricular rhythm. Activation began posteriorly in the outflow tract of the right ventricle. The vector loops (c) (F, frontal, $H$, horizontal, $L S$, left sagittal) correlated well with the electrophysiological findings.

In all patients the accelerated idioventricular rhythm was suppressed when the sinus pacemaker accelerated. During the exercise stress test the arrhythmia progressively disappeared in all at a mean sinus frequency of 85 beats per minute. All patients had a normal effort tolerance and none developed major arrhythmias or ST segment alterations.

\section{CROSS SECTIONAL ECHOCARDIOGRAPHY}

Cross sectional echocardiography showed right ventricular dilatation in three out of five patients (cases 2, 3 , and 4) with a reduced ejection fraction in case 2. The right ventricular outflow tract was dilated in cases 2, 3, and 4. Abnormal regional wall motion or structural alterations or both were detectable in all (see table 2 and fig 3). The left ventricle and the four valves were normal in all.

\section{ELECTROPHYSIOLOGICAL DATA}

In three patients (case 1, 2, 3) basic conduction intervals and refractory periods were normal; no late potentials were detectable in the right ventricle. Accelerated idioventricular rhythm was easily sup- pressed by atrial and ventricular overdrive pacing. Right ventricular mapping and pacing located the origin of accelerated idioventricular rhythm in the outflow tract, posterior ventricle in patients 2 and 3 (fig 2), and anterior ventricle in patient 1 . Accelerated idioventricular rhythm or other arrhythmias could not be induced by the above techniques or extrastimuli.

\section{HAEMODYNAMIC DATA}

The right ventricle was enlarged in two (cases 2 and 3 ) of the three patients examined (end diastolic volume $=149$ and $122 \mathrm{ml} / \mathrm{m}^{2}$ respectively) with an ejection fraction of 44 and $52 \%$ respectively (fig 4 ). The right ventricular outflow tract was enlarged and the trabecular framework was abnormal in both; there was bulging of the inferior wall in patient 2 and of the lateral wall in patient 3 . Both patients also had abnormal regional wall motion (table 2 ). The third patient (case 1) had an end diastolic volume and ejection fraction of $70 \mathrm{ml} / \mathrm{m}^{2}$ and $55 \%$ respectively; there was apical hypokinesia, slightly abnormal trabeculae, and bulging of the superoanterior right 
Table 2 Right ventricular angiographic, cross sectional echocardiographic, and histological data

\begin{tabular}{|c|c|c|c|c|c|}
\hline & Case 1 & Case 2 & Case 3 & Case 4 & Case 5 \\
\hline $\begin{array}{l}\text { Angiography: } \\
\text { RV EDV }\left(\mathrm{mi} / \mathrm{m}^{2}\right) \\
\text { RV EF } \\
\text { RV structural } \\
\text { Abnormalities } \\
\text { RV RWMA } \\
\text { RV biopsy }\end{array}$ & $\begin{array}{l}70 \\
55 \% \\
\text { e(mild) } \\
\text { RVOT = d } \\
\text { RVIT = a } \\
\text { Fatty } \\
\text { infiltration }\end{array}$ & $\begin{array}{l}149 \\
44 \% \\
\text { e } \\
\text { RVIT = d } \\
\text { RVIT = a, b } \\
\text { Mild } \\
\text { fibrosis }\end{array}$ & $\begin{array}{l}122 \\
52 \% \\
\text { e } \\
\text { LW }=\mathrm{d} \\
\text { A:b } \\
\text { Fibrosis and } \\
\text { fatty infiltration }\end{array}$ & & \\
\hline $\begin{array}{l}\text { Cross sectional echocardiography: } \\
\text { RV EDV }\left(\mathrm{ml} / \mathrm{m}^{2}\right) \\
\text { RV EF } \\
\text { RVOT diameter }\end{array}$ & $\begin{array}{l}68 \\
60 \%\end{array}$ & $\begin{array}{l}135 \\
48 \%\end{array}$ & $\begin{array}{l}115 \\
55 \%\end{array}$ & $\begin{array}{l}89 \\
61 \%\end{array}$ & $\begin{array}{l}66 \\
63 \%\end{array}$ \\
\hline $\begin{array}{l}\text { (normal }<2.5 \mathrm{~cm}) \\
\text { RV structural } \\
\text { Abnormalities } \\
\text { RV RWMA }\end{array}$ & $\begin{array}{l}2 \\
\text { e(mild) } \\
\text { RVOT }=\mathbf{d} \\
\text { RVIT }=\mathbf{a}\end{array}$ & $\begin{array}{l}3 \cdot 1 \\
\text { e } \\
\text { RVIT }=d \\
\text { RVIT }=a, b\end{array}$ & $\begin{array}{l}2 \cdot 8 \\
e \\
L W=d \\
A=a, b\end{array}$ & $\begin{array}{l}3.6 \\
\text { RVIT }=d\end{array}$ & $\begin{array}{l}2 \cdot 1 \\
\mathbf{f} \\
A=a\end{array}$ \\
\hline
\end{tabular}

RV, right ventricular; RV EDV, right ventricular end diastolic volume (normal value $\left.=81(12.3) \mathrm{ml} / \mathrm{m}^{2}\right) ; \mathrm{RV} \mathrm{EF}$, ejection fraction (normal value $51(8)^{14}$; RV RWMA, right ventricular regional wall motion abnormalities. Right ventricle was divided into four regions: $A$, apex; LW, lateral wall; RVOT, right ventricular outflow tract; RVIT, right ventricular inflow tract.

List of RV RWMA and RV structural abnormalities: (a) hypokinesia; (b) akinesia; (c) systolic dyskinesia; (d) diastolic bulging; (e) derangement of the trabecular framework and papillary muscles; (f) altered echogenicity and nodulation of the moderator band.

ventricular wall. The left ventricle and coronary arteries were normal in all.

\section{ENDOMYOCARDIAL BIOPSY OF THE RIGHT VENTRICLE}

There was pronounced fatty infiltration with myocardial atrophy in patient 1 (fig 5), mild fibrosis in patient 2 , and fibrosis with mild fatty infiltration in patient 3.

\section{Discussion}

Accelerated idioventricular rhythm occurs in 12$30 \%$ of patients with acute inferior myocardial infarction. It is often seen in the first 12 hours, occurs

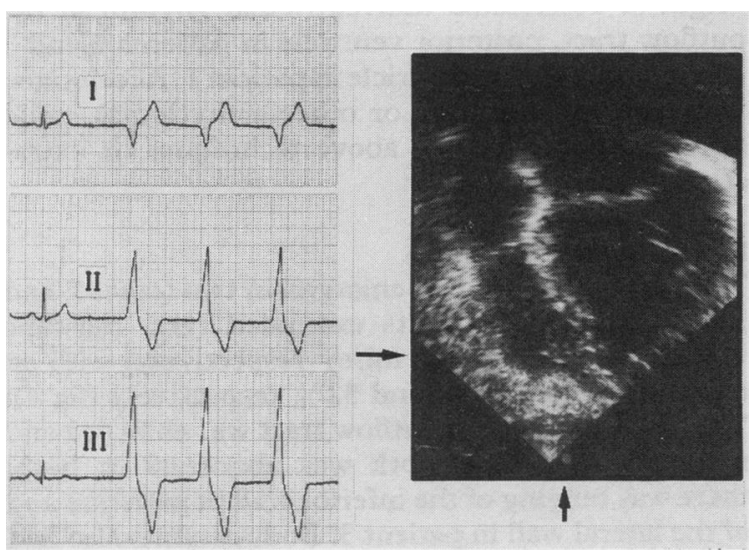

Fig 3 The electrocardiogram of patient 3 during an initiating episode of accelerated idioventricular rhythm. An apical four chamber cross sectional echocardiographic view of the same patient showing sacculation of the lateral wall of the right ventricle and apical akinesia (see arrows). intermittently for a few hours thereafter, and usually resolves after 24 hours. ${ }^{13-6}$

The arrhythmia has also been found in other heart diseases, ${ }^{1367}$ but has been rare when there is no definite cardiac abnormality. We know of few

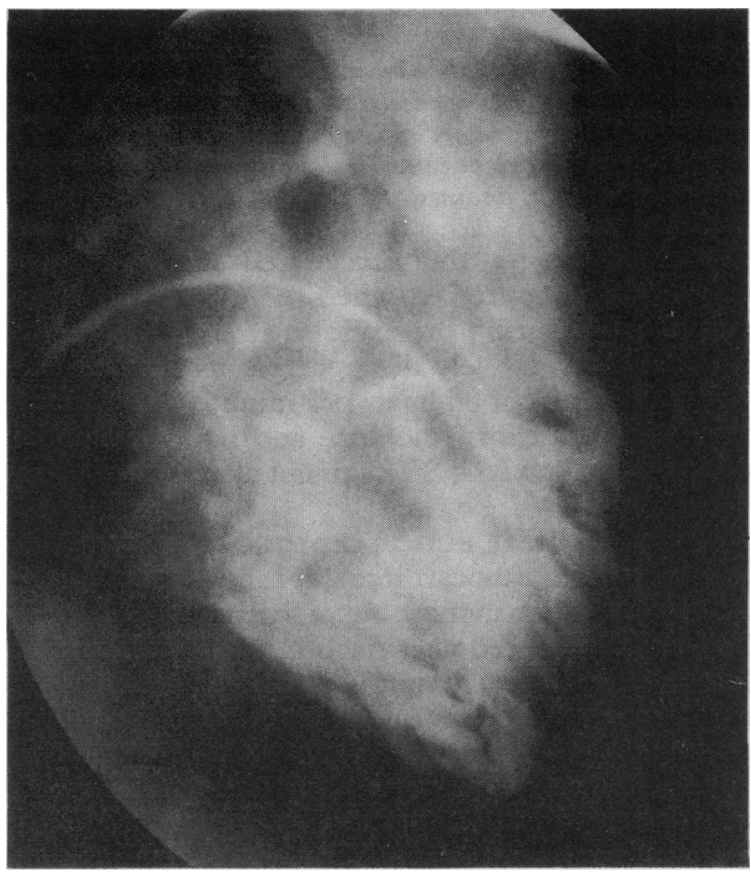

Fig 4 End diastolic, right anterior oblique (long axis) view of a right ventricular angiogram (patient 2). The right ventricular chamber is slightly dilated (volume $149 \mathrm{ml} / \mathrm{m}^{2}$, ejection fraction $44 \%$ ) and there is fissuring of the anterolateral wall. 


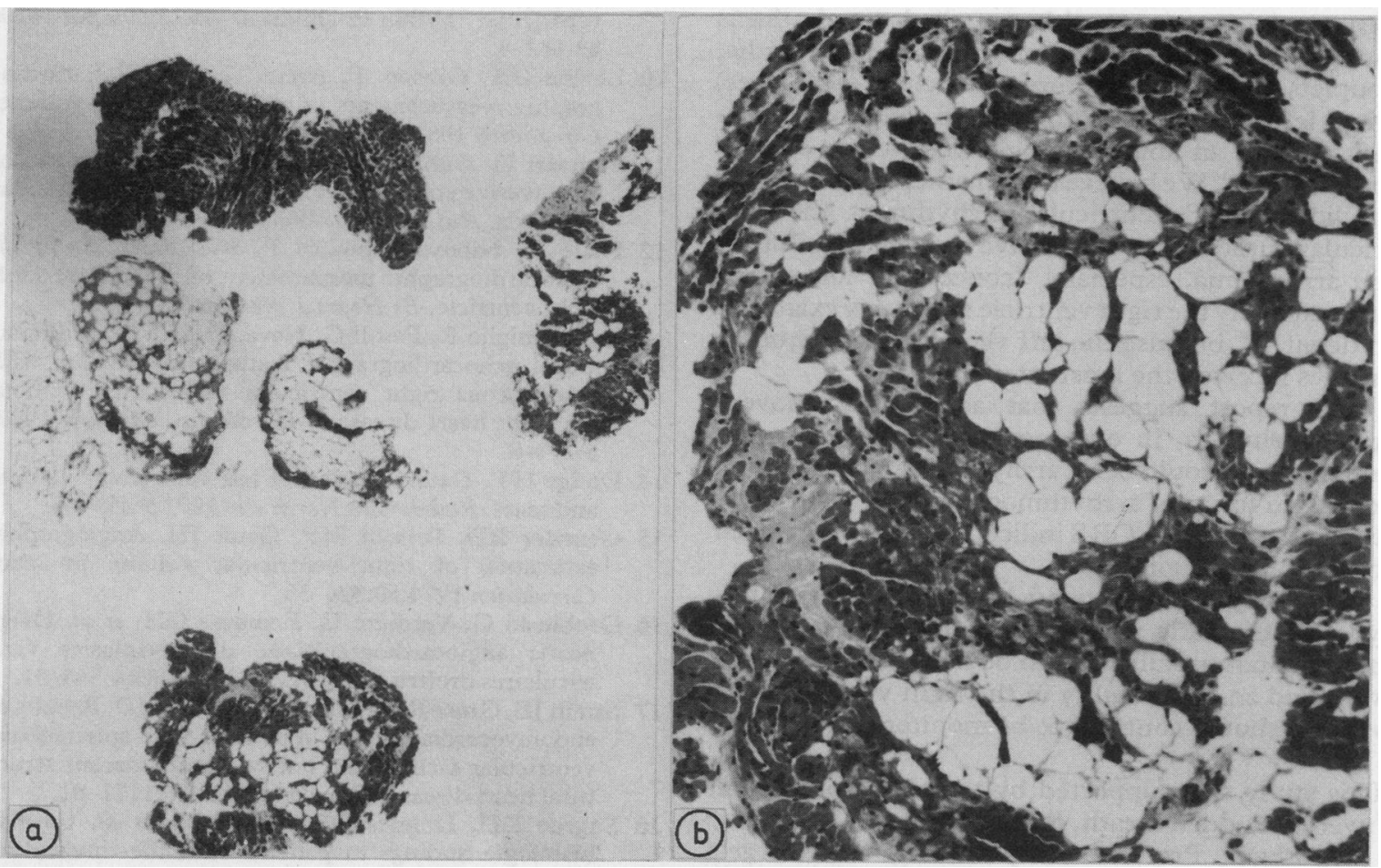

Fig 5 (a) Endomyocardial biopsy specimens of the right ventricular septum (patient 1). Tissue in three of the six was almost entirely adipose. Haematoxylin-eosin, original magnification $\times 10$. (b) The myocardium was slightly sclerotic and infiltrated by adipocytes. Haematoxylin-eosin, original magnification $\times 48$.

previously reported idiopathic cases in young healthy people. ${ }^{1-389}$ There is little published information on basic electrocardiography and the QRS configuration in accelerated idioventricular rhythm. Also echocardiographic and angiographic study is limited and the right ventricle, in particular, has not been fully studied in these patients.

All our patients showed a QRS configuration consistent with left bundle branch block and right axis deviation. The accelerated idioventricular rhythm seemed to be bradycardia dependent; it began as an escape rhythm, with different coupling intervals, and it always ended spontaneously after overdrive suppression by sinus rhythm. The RR intervals were uniform during each episode but accelerate or slow in subsequent episodes, suggesting a sympathetic or parasympathetic influence on the ectopic focus. Accelerated idioventricular rhythm always disappeared during effort when a critical rate (usually $75-102 / \mathrm{min}$ ) was reached. The rhythm was not inducible nor was it accelerated by electrophysiological techniques. All the above patterns were typical of an ectopic automatic rhythm without parasystole and reentry.

Standard electrocardiography, vectorcardio- graphy, and endocardial mapping during the electrophysiological study showed that the accelerated idioventricular rhythm originated in the right ventricular outflow tract (figs 1 and 2). In all our patients data from the cross sectional echocardiography and haemodynamic-angiographic studies excluded valvar, left ventricular, and coronary heart diseases and showed structural or wall motion abnormalities of the right ventricle or both. Endomyocardial biopsy specimens showed fibrosis and/or fatty infiltration, particularly in case 1 (fig 5).

These alterations may be associated with minor concealed forms of arrhythmogenic right ventricular dysplasia. ${ }^{17-22}$ This disease has many forms-from a generalised involvement of the entire ventricle ${ }^{23-25}$ with global dilatation, altered haemodynamic function, and reduced ejection fraction, to mild focal lesions characterised by an almost normal clinical picture and normal features on invasive and noninvasive investigation. ${ }^{131720-2226-31}$ Only a careful examination of the right ventricle, with endomyocardial biopsy in selected cases, can detect structural and/or regional wall motion abnormalities, which might represent a forme fruste of the condition.

Right ventricular dysplasia should always be 
suspected in patients with ventricular arrhythmia (sustained and transient ventricular tachycardia, couplets, isolated premature ventricular complexes) when left bundle branch block and right axis deviation suggest an abnormal right ventricular outflow tract. ${ }^{20-2729}{ }^{32-34}$ We believe that in other reported cases of "idiopathic" ventricular arrhythmias the ventricular outflow tract could have been responsible for the arrhythmia, especially "concealed" forms, but unfortunately the right ventricle was rarely examined in detail, ${ }^{35-40}$ because the left ventricle and coronary arteries received the most attention.

Our report suggests that accelerated idioventricular rhythm, in our cases caused by enhanced automaticity, could be an arrhythmia associated with concealed forms of arrhythmogenic right ventricular dysplasia, when the $Q R S$ indicates a right ventricular infundibular origin.

Follow up of our patients has confirmed that this type of automatic ventricular arrhythmia is benign and does not usually need to be treated. But because we found an abnormality in the right ventricle such patients should continue to be monitored.

This study was supported by the target project on Juvenile Sudden Death, Regione Veneto, Italy.

We thank Professor A J Camm, St George's Hospital, London for reviewing our typescript.

\section{References}

1 Medvedowski JL, Donzeau JP, Nicolai P, Barnay C, Blache E. Accelerated idioventricular rhythm. In: The arrhythmia working group of the French Cardiac Society, eds. The cardiac arrhythmias. Paris: RousselUclaf, 1979:218-27.

2 Bisset GS, Janos GG, Gaum WE. Accelerated idioventricular rhythm in the newborn infant. $J$ Pediatr 1984;104:247-9.

3 Massumi R, Ali N. Accelerated isorhythmic ventricular rhythms. Am J Cardiol 1970;26:170-85.

4 Soyza N, Bisset JK, Kane J, Murphy ML, Doherty JE. Association of accelerated idioventricular rhythm and paroxysmal ventricular tachycardia in acute myocardial infarction. Am J Cardiol 1974;34:667-70.

5 Lichstein E, Ribas-Meneclier C, Gupta PK, Chadda $\mathrm{KD}$. Incidence and description of accelerated ventricular rhythm complicating acute myocardial infarction. Am J Med 1975;58:192-8.

6 Waynberger M, Motte G, Coumel P, Slama R, Bouvrain $Y$. Les rythmes idioventriculaires accelérés (ou "tachycardies ventriculaires lentes"). Arch Mal Coeur 1973;3:709-23.

7 Davidson RM. Chronic accelerated ventricular rhythm. $J$ Electrocardiol 1976;9:249-54.

8 Chung K-Y, Walsh TJ, Massie E. Ventricular parasystolic tachycardia. Br Heart J 1965;27:392-400.

9 Gaum WE, Biancaniello T, Kaplan S. Accelerated ventricular rhythm in children. Am J Cardiol 1979; 43:162-4.

10 Levine GA, Gibson T, Aretz T, et al. Echocardiographic measurements of right ventricular volume. Circulation 1984;69:497-505.

11 Manyari D, Duff HJ, Kostuk W, et al. Usefulness of noninvasive studies for diagnosis of right ventricular dysplasia. Am J Cardiol 1986;57:1147-53.

12 Foale R, Nihoyannopoulos P, McKenna W, et al. Echocardiographic measurement of the normal adult right ventricle. $B r$ Heart $J$ 1986;56:33-44.

13 Scognamiglio R, Fasoli G, Nava A, et al. Two dimensional echocardiographic features in patients with spontaneous right ventricular tachycardia without apparent heart disease. J Cardiovasc Ultrason 1987; 6:113-8.

14 Dodge HT. Determination of left ventricular volume and mass. Radiol Clin North Am 1971;9:459-65.

15 Gentzler RD, Briselli MF, Gault JH. Angiographic estimation of right ventricular volume in man. Circulation 1974;50:324-39.

16 Drobinski G, Verdière G, Fontaine GH, et al. Diagnostic angiocardiographique des dysplasies ventriculaires droites. Arch Mal Coeur 1985;4:544-51.

17 Strain JE, Grose RM, Factor SM, Fisher JD. Results of endomyocardial biopsy in patients with spontaneous ventricular tachycardia but without apparent structural heart disease. Circulation 1983;6:1171-81.

18 Sugrue DD, Holmes DR, Gersh BJ, et al. Cardiac histologic findings in patients with life-threatening ventricular arrhythmias of unknown origin. J Am Coll Cardiol 1984;4:952-7.

19 Hosenpud JD, McAnulty JH, Niles NR. Unexpected myocardial disease in patients with life threatening arrhythmias. Br Heart J 1986;56:55-61.

20 Slama R, Leclerq JF, Coumel PH. Paroxismal ventricular tachycardia in patients with apparently normal hearts. In: Zipes DP, Jalife JJ, eds. Cardiac electrophysiology and arrhythmias. Orlando and London: Grune and Stratton 1985:545-52.

21 Nava A, Canciani B, Scognamiglio R, et al. La tachicardia e la fibrillazione ventricolare nel ventricolo destro aritmogeno (displasia aritmogena del ventricolo destro). Spettro clinico ed elettrocardiografico. G Ital Cardiol 1986;16:741-9.

22 Nava A, Scognamiglio R, Thiene G, et al. A polymorphic form of familial arrhythmogenic right ventricular dysplasia. Am J Cardiol 1987;59:1405-9.

23 Rossi P, Massumi A, Gillette P, Holl R. Arrhythmogenic right ventricular dysplasia: clinical features, diagnostic techniques, and current management. $\mathrm{Am}$ Heart J 1982;103:415-20.

24 Markus FI, Fontaine GH, Guiraudon G, et al. Right ventricular dysplasia: a report of 26 adult cases. Circulation 1982;65:384-97.

25 Fontaine G, Frank R, Tonet JL, et al. Arrhythmogenic right ventricular dysplasia: a clinical model for the study of chronic ventricular tachycardia. Jpn Circ J 1984;48:515-26.

26 Dungan TW, Garson A, Gillette PC. Arrhythmogenic right ventricular dysplasia: a cause of ventricular tachycardia in children with apparently normal 
hearts. Am Heart $J$ 1981;102:745-50.

27 Fauchier JP, Desveaux B, Cosnay P, Raynaud P, Philippe L, Itti R. Troubles du rythme ventriculaire complexes du sujet jeune apparemment sain. Arch Mal Coeur 1985;78:1333-43.

28 Pietras RJ, Lam W, Bauernfeind R, et al. Chronic recurrent right ventricular tachycardia in patients without ischemic heart disease: clinical hemodynamic and angiographic findings. Am Heart J 1983;105: 357-66.

29 Palileo EV, Ashley WW, Swiryn S, et al. Exercise provocable right ventricular outflow tract tachycardia. Am Heart J 1982;104:185-92.

30 Deal BJ, Miller SM, Scagliotti D, et al. Ventricular tachycardia in a young population without overt heart disease. Circulation 1986;6:1111-8.

31 Thiene G, Nava A, Corrado D, Rossi L, Pennelli N. Right ventricular cardiomyopathy and sudden death in young people. $N$ Engl J Med 1988;129-33.

32 Reiter JM, Smith WM, Gallagher JJ. Clinical spectrum of ventricular tachycardia with left bundle branch morphology. Am J Cardiol 1983;51:113-21.

33 Rowland E, McKenna WJ, Sugrue D, Barclay R, Foale RA, Krikler DM. Ventricular tachycardia of left bundle branch block configuration in patients with isolated right ventricular dilatation. Clinical and electrophysiological features. $\mathrm{Br}$ Heart $J$ 1984;51:
15-24.

34 Foale RA, Nihoyannopoulos P, Ribeiro P, et al. Right ventricular abnormalities in ventricular tachycardia of right ventricular origin: relation to electrophysiological abnormalities. Br Heart $J$ 1986;56: 45-54.

35 Pedersen DH, Zipes DP, Foster RP, Troup PJ. Ventricular tachycardia and ventricular fibrillation in a young population. Circulation 1979;60:988-97.

36 Rocchini AP, Chun PO, Dick M. Ventricular tachycardia in children. Am J Cardiol 1981;47:1091-7.

37 Rahilly GT, Prystowsky EN, Zipes G, et al. Clinical and electrophysiologic findings in patients with repetitive monomorphic ventricular tachycardia and otherwise normal ECG. Am J Cardiol 1982;50: 459-68.

38 Vetter VL, Josephson ME, Horowitz LN. Idiopatic recurrent sustained ventricular tachycardia in children and adolescents. Am J Cardiol 1981;47:315-21.

39 Buxton AE, Waxman HL, Marchlinsky FE, Simson MB, Cassidy D, Josephson ME. Right ventricular tachycardia: clinical and electrophysiologic characteristics. Circulation 1983;68:917-27.

40 Holt PM, Wainwright RJ, Curry PVL. Right ventricular outflow tract tachycardias in patients without apparent structural heart disease. Int J Cardiol 1986;10:99-110. 